\title{
LOS ABOGADOS Y LAS PALABRAS. UNA PROPUESTA PARA FORTALECER COMPETENCIAS INICIALES EN LOS ESTUDIANTES DE DERECHO*
}

\author{
RODRIGO COLOMA ** \\ ClaUdio AgÜERo SAN JUAN ${ }^{* * *}$
}

RESUMEN: Un número significativo de los jóvenes que inician sus estudios de derecho en nuestro país, no logra adquirir oportunamente muchos de los aprendizajes previstos en sus respectivos planes de estudios. Aquello, como es obvio, impacta negativamente en una serie de indicadores de éxito del proceso formativo, como es el caso de la retención de estudiantes y del avance curricular. Luego de explorarse las posibles causas del problema aludido, en el presente artículo se identifican y analizan dos competencias del ámbito de la lecto-escritura cuya temprana nivelación debiera provocar un impacto especialmente positivo en la producción de nuevos aprendizajes. La propuesta -que supone que en las facultades de derecho se trabaje focalizada y contextualizadamente con los estudiantes que se encuentren en una posición desaventajada- apunta a que tempranamente se aborden con ellos asuntos de naturaleza semántica, gramatical y pragmática del lenguaje del derecho. No asumir aquello hará difícil que los que hoy en día son estudiantes lleguen a comprender y a construir una clase de textos y de discursos, que les resultarán claves para insertarse en el futuro en la comunidad disciplinaria conformada por jueces y abogados.

PALABRAS CLAVE: Alfabetización académica - enseñanza del Derecho - formación por competencias - competencias profesionales - textos y discursos jurídicos.

Los problemas que son tratados en el presente artículo fueron inicialmente abordados en la Asistencia Técnica $N^{\circ} 3$ del proyecto MECESUP UCN0802 "Capacitación en diseńo e implementación de plan de nivelación de competencias básicas de alumnos de primer ańo", a cargo del primero de los autores.

Fecha de recepción: 29 de agosto de 2011

Fecha de aceptación: 27 de diciembre de 2011

** Profesor Adjunto de las facultades de Derecho de las universidades Alberto Hurtado y Católica de Temuco. Doctor en Derecho. Correo electrónico: rcoloma@uahurtado.cl

*** Profesor de la Facultad de Derecho de la Universidad Austral de Chile y miembro del Centro de Desarrollo Docente de la Universidad de Valparaíso. Doctor en Ciencias Humanas, Magíster en educación y Abogado. Correo electrónico: claudio.aguero@uv.cl 


\section{LAWYERS AND WORDS. A PROPOSAL TO STRENGTHEN THE INITIAL COMPETENCES OF LAW STUDENTS}

ABSTRACT: A significant number of young people who begin their studies of law in our country, can not get timely many lessons in their curriculum. That, of course, impacts negatively on a number of indicators of success of the training process, such as retention of students and curriculum development. After exploring the possible causes of the problem mentioned, this article identifies and discusses two powers in the field of literacy (reading and writing skills) whose early leveling should provoke a positive impact especially in the production of new learning. The proposal, which is intended to be worked out by the school of laws focused on and in context with the students who are in a disadvantaged position, refers to early indications and issues which are related to semantic in nature, grammatical and pragmatic language of law. Do not assume that, it will make difficult for those who are students today come to understand and build a type of texts and discourses, which will be the key to be inserted in a future disciplinary community made up of judges and lawyers.

KEY WORDS: Academic alphabetization - legal education - competence formation - professional competence - legal texts and speeches

\footnotetext{
"He sido condenado a la horca. Abominablemente he vencido: he comunicado a Berlín el secreto nombre de la ciudad que deben atacar. Ayer la bombardearon; lo leí en los mismos periódicos que propusieron a Inglaterra el enigma de que el sabio sinólogo Stephen Albert muriera asesinado por un desconocido, Yu Tsun. El jefe ha descifrado ese enigma. Sabe que mi problema era indicar (a través del estrépito de la guerra) la ciudad que se llama Albert y que no hallé otro medio que matar a una persona de ese nombre..."

Jorge Luis Borges. El jardin de los senderos que se bifurcan
}

\section{INTRODUCCIÓN}

Es una cuestión casi de sentido común hacer depender gran parte del éxito que se pueda alcanzar en cualquier experiencia formativa del domi- 
nio que los aprendices demuestren sobre un conjunto de competencias consideradas clave para la adquisición de nuevos saberes, habilidades y/o valores ${ }^{1}$. Así, por ejemplo, si lo que pretendemos es enseńar ecuaciones a nuestra hija de 13 años, previamente a acometer dicha tarea, debiésemos preocuparnos de constatar si ella sabe suficiente aritmética, si posee disciplina elemental para el estudio y si está genuinamente interesada por aprender álgebra. Si así no fuere la experiencia terminará en un fracaso o, en el mejor de los casos, tomará mucho más tiempo del que inicialmente habíamos previsto; ello por cuanto habrá que nivelar sus déficits formativos en forma previa o coetánea a la realización de actividades encaminadas al aprendizaje de ecuaciones.

El asunto recién indicado, por cierto, incide en que quienes trabajan seriamente en educación deban preocuparse por aplicar oportunamente los filtros necesarios que impidan que personas que carezcan de suficiente preparación sean admitidas para participar en determinadas instancias formativas. Esto no obsta, eso sí, a que haya situaciones intermedias en las cuales resulte difícil llevar a cabo un proceso de selección rigurosa, por cuanto el dominio con que cuentan los aprendices de aquellas competencias básicas que se han definido como relevantes podría ser solo parcial. Ante ese escenario, no sería de extrańar que se produzca un debilitamiento en las barreras de entrada, por cuanto algunos de los déficits detectados serían, en principio, susceptibles de ser compensados con una buena dosis de esfuerzo. Aquello alcanzará especial relevancia si se asocia a un argumento que se encuentra a la mano en sociedades afectadas por la desigualdad y que se traduce en el hecho de que establecer filtros exigentes priva, en especial, a los más desaventajados del acceso a una experiencia formativa que facilitaría su ascenso social, económico y/o cultural.

El panorama, entonces, va tornándose borroso y las exigencias del sentido común se van difuminando, lo que incide en que el punto de partida en que se encuentra el aprendiz frecuentemente deje de ser tomado suficientemente en serio. Sin llegar a ser un caso paradigmático de ceguera ante los déficits formativos de los estudiantes que acceden a la educación superior, hay buenas razones para sostener que entre quienes pretenden acceder (o acceden) a la carrera de derecho, existe un número significativo que no está suficientemente capacitado, en principio, para superar exitosamente las exigencias que les serán impuestas. Tal situación puede llevar a las facultades de derecho a reaccionar como sigue:

1 De manera consistente con lo indicado, es útil llamar la atención en cuanto a que una de las mayores aportaciones que se le reconocen al psicólogo ruso Lev Vygotsky refiere a la construcción de categorías que den cuenta del estado en que se encuentra un sujeto que enfrenta una situación de aprendizaje. En conformidad a ella, Vygotsky distinguió entre zona de desarrollo real, zona de desarrollo próximo y zona de desarrollo potencial. Ver en VyGOTSKY, L.S. (1978). Mind in society: The development of higher psychological processes. Cambridge, MA: Harvard University Press, p. 86. 
a) Reducir las exigencias para el egreso (los déficits que aquejan a los alumnos aceptados determina, entonces, de manera fuerte el perfil de egreso).

b) Aumentar la selectividad en el acceso a los estudios, a través de mayores exigencias para el ingreso.

c) Mejorar la eficiencia de las prácticas pedagógicas y, en especial, nivelar oportunamente los déficits iniciales que aquejan a quienes se matriculan en la carrera de derecho.

En lo que sigue, intentaremos dar algunas pistas acerca de la viabilidad de la última de las opciones seńaladas. Sin perjuicio de ello, lo que a continuación se dirá no es plenamente aplicable a todas las facultades de derecho del país, ya que en unas pocas de ellas se cuenta con importantes filtros de selección que propenden a una cierta homogeneización entre sus matriculados. Tales filtros refieren fundamentalmente a la exigencia de un elevado puntaje en la PSU (prueba de selección universitaria) lo cual resulta posible al estar dotadas tales instituciones de bastante prestigio a nivel nacional ${ }^{2}$, como también por la existencia de redes sociales que inciden en una alta empleabilidad de sus egresados y, consecuencialmente, en el interés de los estudiantes mejor preparados en la enseńanza secundaria para ingresar en ellas.

En nuestro país el mecanismo mayoritariamente utilizado para determinar el acceso a la carrera de derecho está determinado por el puntaje que se obtenga en la prueba de selección universitaria (PSU) administrada por el DEMRE. Sin embargo, este sistema no es universal. En algunas universidades masivas no existe - de hecho- un proceso de selectividad y cualquier estudiante que cuente con los recursos para pagar la matrícula puede ingresar. En estas instituciones los problemas para conseguir cohortes que cumplan con un perfil de ingreso mínimo son graves. En otras palabras, muchos de esos estudiantes, aunque tengan el deseo o la aspiración de lograr un título universitario, no cuentan con las competencias mínimas para enfrentar exitosamente un proceso de enseńanza, incluso, con un nivel de exigencia bajo. En los casos más dramáticos, el tiempo y los costes de la nivelación son extremadamente altos, lo cual incide en que estas instituciones de educación superior tiendan a desentenderse de ellos, en cuanto a su calidad de sujetos que requieren de un proceso formativo especial.

Durante el primer ańo, la existencia de algunas asignaturas complejas, junto a la frecuente utilización de textos difíciles impactan en que los estudiantes más desaventajados vayan quedando rezagados (los profesores

2 Esto puede advertirse al cruzar los puntajes mínimos PSU para el ingreso a la carrera de Derecho y los rankings construidos a partir de percepciones de encuestados, como es el caso del que realiza la revista Qué Pasa. Ver http://www.ues.cl/especiales/Ranking_que_pasa_2009/ carreras/derecho 
no cuentan con el apoyo necesario para hacerse cargo de ellos). Una alternativa posible es entregar estas competencias en programas de formación inicial como bachilleratos o planes de formación previos a la entrada a la carrera. Naturalmente, el problema es el tiempo, ya que un estudiante podría estar uno, dos o tres años en estos programas antes de estar en condiciones de ingresar a estudiar derecho.

\section{1) El CONTEXTO DE LA FORMACión DE LOS ABOGADOS}

El análisis que llevaremos a cabo parte de la premisa de que el contexto que rodea a la formación universitaria, y específicamente a los estudios de derecho, ha experimentado cambios muy importantes en los últimos 30 ańos. Esto lleva a que perseverar en una serie de prácticas pedagógicas que antes se consideraban eficaces, hoy en día conduciría a un desastre formativo. Sin pretensiones de enumerar de modo exhaustivo y excluyente aquellos factores que han cambiado el escenario de la formación universitaria, es posible afirmar que los principales han sido los siguientes: i) cambios en el mercado de la educación superior; ii) cambios tecnológicos y, iii) cambios sociales que han impactado en la clase de tareas que se espera que sean desempeñadas por los abogados. A pesar de que cada factor señalado es complejo y cuenta por sí solo con méritos suficientes como para ser discutidos separada y exhaustivamente, a continuación realizaremos un análisis breve que esperamos resulte suficiente para efectos de fijar uno de los soportes de la propuesta que más adelante se plantea.

Como recurrentemente se llama la atención en conversaciones y en textos especializados, en Chile, en los últimos treinta ańos, ha aumentado de forma explosiva el número de estudiantes de derecho y junto a ello se ha producido una diversificación del mercado universitario ${ }^{3}$. Esta transformación fue impulsada por medidas políticas y económicas las cuales han incidido en que en el día de hoy encontremos, por un lado, muchos estudiantes provenientes de múltiples contextos socioeconómicos y culturales y, por el otro, un sistema universitario que no ha sido diseńado para asumir el desafío de producir aprendizajes en grupos humanos altamente heterogéneos. En otras palabras, las prácticas pedagógicas dominantes en las universidades no se hacen cargo de la circunstancia de que los estudiantes que ingresan a sus aulas posean competencias y conocimientos previos muy diversos entre sí.

3 Brunner, José Joaquín y ElaCQUA, Gregory (2003) Informe de capital humano, Universidad Adolfo Ibáńez. Disponible en: http://www.oei.es/etp/informe_capital_humano_chile_brunner.pdf 
Es importante tener en cuenta que en la actualidad la oferta universitaria se encuentra altamente segmentada. En Chile hay más de 45 escuelas o facultades de Derecho, la mayoría de las cuales ha tenido una vida corta, lo cual repercute en que nazcan sospechas de parte de los mismos abogados respecto a la calidad de la formación que en ellas se otorga ${ }^{4}$. Hasta la fecha, solo diez de los programas ofrecidos han sido acreditados en alguna oportunidad por la Comisión Nacional de Acreditación, encontrándose solo cinco resoluciones vigentes a agosto de 20115. Lo expresado ha llevado a algunos a discutir y a explorar (tímidamente) acerca de posibles mecanismos de certificación y habilitación profesional; ello en cuanto a que los que actualmente existen, parecieran no garantizar suficientemente las competencias profesionales de todos los recién titulados.

En Chile los requisitos para ser abogado están determinados en el artículo 523 del código orgánico de tribunales. En esa disposición, además de establecerse una edad mínima y demostrar buena conducta previa, se exige contar con el grado de licenciado en ciencias jurídicas otorgado por una universidad, como asimismo haber cumplido con una práctica profesional de seis meses de duración. Aquellas exigencias, por única vez, son bastante menores si se les compara con las que se aplican habitualmente en otros países reconocidos como desarrollados.

La única experiencia conocida por los autores en cuanto a revisión de los requisitos para acceder a la profesión de abogado y en que se ha involucrado a varios actores relevantes, ha correspondido a la creación de un Comité de Certificación y Habilitación para la Profesión de Abogado. Este fue constituido (pero no formalizado) por el Ministerio de Educación en conformidad al artículo $5^{\circ}$ transitorio de la ley No 20.129, siendo integrado por representantes de distintas universidades nacionales, del Ministerio de Justicia, de la División de Educación Superior, de la Corte Suprema, del Colegio de Abogados, del Ministerio Público, de la Defensoría Penal Pública y de la Confederación de la Producción y del Comercio. En junio de 2010, y luego de cinco meses de trabajo, el Comité se disolvió debido a que no fue expresamente ratificado por el nuevo Gobierno, aduciéndose que este habría cambiado las estrategias para enfrentar la habilitación y certificación profesional.

En 1980 había solo seis carreras de Derecho, contando separadamente a dos que operaban como sedes.

5 Es difícil interpretar estas cifras en una sola dirección: más bien hay razones para ser precavido al momento de atribuir valor a la acreditación de las carreras de derecho. Una muestra de ello puede extraerse del hecho de que uno de los ranking más valorados por las facultades de derecho $-y$ que no se construye a partir de las percepciones, sino en datos como la productividad académica o la formación de los docentes (nos referimos al ranking elaborado por la revista América \& Economía) - no considera entre sus variables el hecho de si la carrera de derecho está o no acreditada. Ver http://rankings.americaeconomia.com/2010/ mejores-universidades-chile/metodologia.php 
El segundo factor que ha modificado el contexto formativo de los abogados -según fue sugerido en líneas precedentes- se vincula a los cambios tecnológicos de las últimas décadas. El surgimiento de Internet, que trajo consigo el acceso masivo a la información en soporte digital y un importante cambio sociocultural asociado al surgimiento de redes sociales, ha implicado profundas modificaciones en la forma en que las personas acceden, valoran y administran la información. Esto es importante al menos en tres planos. Primero: parece ser que los conocimientos enciclopédicos altamente prestigiados en épocas pasadas ya no son valorados 'del mismo modo'. Los estudiantes de hoy pueden acceder, con un par de clicks, a datos que antańo solo eran accesibles a un grupo de privilegiados, conformado principalmente por abogados, jueces e investigadores. De esta manera, se ha producido una externalización de la memoria jurídica, la que ha pasado a conservarse en bases de datos y que solo precisa estar disponible en nuestras mentes en instancias evaluativas, en audiencias judiciales, en congresos disciplinarios y en algunas de las entrevistas con clientes. Segundo: la extraordinaria facilidad para comunicarse en simultáneo y de manera escrita con distintos lugares del mundo, haciendo para ello uso de redes sociales como Facebook o Google+, enviando mensajes desde teléfonos celulares o utilizando el correo electrónico, han incidido en una creciente sustitución (especialmente entre los más jóvenes) de muchos de nuestros códigos lingüísticos por otros más económicos. Pero eso no es todo, pues si a esta verdadera pasión por lo inmediato se le ańade la forma dinámica de organización de los textos en soporte electrónico -la que permite ir saltando de uno a otro en unos pocos segundos- se va produciendo un decaimiento del pensamiento lineal que es propio de la construcción y de la lectura de textos argumentativamente complejos, los cuales tradicionalmente han sido (y siguen siendo) muy apreciados por la cultura jurídica ${ }^{6}$. Tercero: la profesión jurídica ha perdido relevancia en lo que respecta a la consulta de asuntos sencillos que clientes alfabetizados digitalmente pueden aclarar por sus propios medios al acceder a fuentes de información que hasta hace poco solo los abogados conocían.

En cuanto a lo que hemos anunciado como cambios sociales que impactan en el ejercicio de la profesión jurídica, es preciso indicar que, al

6 De este fenómeno se ha ido llamando la atención en distintos ámbitos. Los estudios más interesantes, probablemente, son aquellos que lo relacionan con recientes desarrollos en el campo de la neurociencia. Así, en un reciente libro de Nicholas Carr (fácilmente asequible para los no expertos), se da cuenta de algunas investigaciones que apuntan a que estos cambios tecnológicos estarían modificando nuestros circuitos neuronales. Esto es lo que se conoce como neuroplasticidad o plasticidad cerebral que es una forma de adaptación de nuestro cerebro a nuevas circunstancias ambientales o fisiológicas. CARR, Nicholas (2010) Superficiales ¿Qué está haciendo Internet con nuestras mentes? Bogotá: Taurus, 2011. Trad. de Pedro Cifuentes del original The Shallows. What the Internet is doing to our brains? W. W. Norton \& Company. 
igual que en muchos otros países, en Chile estos cambios han sido profundos no habiendo señales, al menos en el corto plazo, que aminorarán en los ańos venideros. Las progresivas demandas ciudadanas por un pacto social más igualitario $\mathrm{y}$, a la vez, por mejores garantías a los derechos fundamentales que amparan a grupos minoritarios, han empezado a impactar en los estudios jurídicos y en los parámetros centrales de evaluación del desempeńo de los abogados. Hoy, ninguna 'buena' carrera de Derecho debiera descuidar la enseñanza de los problemas constitucionales y administrativos vinculados a los derechos fundamentales, porque esas instituciones saben que para ser calificado como un 'buen' abogado es necesario dominar bien cómo resguardar estos derechos. A ello debe sumarse una mayor exigencia de trabajo interdisciplinario provocada por una mayor sofisticación en los litigios en que se reclama la responsabilidad del Estado o profesional, como también por una creciente exigencia de articulación de sistemas normativos, fruto de la globalización.

En otro orden de cosas, se ha ido produciendo un mejor acceso a la justicia puesto que un porcentaje más elevado de la población puede pagar por servicios profesionales, y de la mano a ello se ha profesionalizado la persecución penal con la creación del Ministerio Público. Asimismo, se ha mejorado la asistencia gratuita a través de la creación de defensorías a cargo exclusivamente de abogados.

\section{2) LA ALFABETIZACIÓN ACADÉMICA}

Dejando a un lado a los estudiantes talentosos y a aquellas instituciones que pueden aplicar filtros exigentes, la mayor parte de las carreras de Derecho forman a una gran cantidad de estudiantes que tienen diversas carencias educativas. Por razones de claridad argumental diremos que todos los estudiantes que no cuentan con una o varias destrezas que exigen los estudios de derecho -es decir, quienes no cumplen con el perfil de ingreso- son estudiantes 'desaventajados'. Naturalmente, esas carencias son múltiples y se presentan de un modo gradual. A pesar de ello, solo nos referiremos a un grupo de competencias que entran en la familia de los asuntos propios de lectoescritura. Al fijar este objetivo, no estamos diciendo que estas dificultades sean las únicas que debiesen ser trabajadas para disminuir la distancia entre el perfil de ingreso planificado y el efectivamente logrado por una cohorte determinada. En otras palabras, estamos asumiendo que las competencias de lectoescrituras son prioritarias - mas no las únicas ${ }^{7}$ al momento de iniciarse los estudios de derecho y que por

Así, por ejemplo, un impacto muy elevado en lo que será el desempeño profesional corresponde a las llamadas habilidades blandas. Ver presentación del Premio Nobel James Heckman http://www.mundovision.cl/webinar2.php?id=869 (su intervención es a partir de 01:47:30). 
ello deberían ser fortalecidas. De este modo, en lo que sigue situaremos el foco en el fortalecimiento de las competencias asociadas a las tareas de lectura y escritura de textos especializados buscando delinear algunos de los principios que deberían inspirar el trabajo pedagógico con estudiantes desventajados.

Muchos de los estudiantes que ingresan a estudiar derecho no han desarrollado suficientemente algunas competencias de lecto-escritura que resultan claves para comprender, evaluar o sintetizar textos especializados de la disciplina. Una explicación corriente para este fenómeno es la carencia de capital cultural; es decir, hay estudiantes que no cuentan con las herramientas que les permitirían dar significado a las prácticas de lectura y escritura propias del trabajo universitario, en términos consistentes como sería exigible a quienes pretendan formar parte de la comunidad de jueces y abogados. En palabras simples: no todos los estudiantes tienen clara conciencia de cómo el lenguaje escrito es leído y comprendido por los demás y, una proporción mucho menor conoce las particularidades del lenguaje jurídico; en especial, su búsqueda de precisión y de univocidad en el uso de las palabras ${ }^{8}$.

A diferencia de lo que ocurre en la educación secundaria, en donde se trabaja con materiales graduados y especialmente preparados para los estudiantes, en la universidad los estudiantes se enfrentan con textos pensados por y para especialistas. Los textos que se dan a leer en las facultades de derecho son de complejidad variable, se traslapan en términos de presentar posiciones opuestas o redundantes, no pretenden abarcar todos los contenidos de los programas de la respectiva asignatura y presentan una estructura narrativa diferente. Abordar estos cuerpos de información obliga a los estudiantes a desplegar nuevas estrategias para identificar la información importante, para contrastar los resultados de diversas investigaciones o las opiniones de diversos autores y para seleccionar qué es lo que deben aprender. El problema es que muchas de estas operaciones cognitivas no han sido suficientemente entrenadas en los colegios y el estudiante, por ejemplo, no sabe cómo distinguir las perspectivas teóricas ni cómo ordenar las tipologías conceptuales de un modo diferente al disponible en el texto que se le presenta. Por otro lado, las tareas de escritura típicas de los colegios se orientan a la reproducción de información y a la generación de opiniones personales y subjetivas, antes que a la construcción de textos argumentativos. Los estudiantes no saben justificar sus opiniones usando el aparataje conceptual que estudian ni escribir textos

8 En este sentido se expresan en otro sector del conocimiento Assous, Gisèle y AtTar, Colette (2003) "Leer un texto matemático". En El poder de leer. Técnicas, procedimientos y orientaciones para la enseñanza y aprendizaje de la lectura. Barcelona: Editorial Gedisa, pág. 182. 
que den cuenta de las razones que soportan una determinada decisión? El primer obstáculo que debe superar el estudiante desaventajado es, entonces, la lectura de los materiales que los profesores le distribuyen. Leer y escribir están, al fin y al cabo, en una relación dialéctica ${ }^{10}$.

El segundo obstáculo que, con frecuencia, deben sortear los estudiantes está representado por sus propios profesores. Un académico universitario habitualmente asume que las estrategias cognitivas de procesamiento y de generación de información se aprenden por imitación y que son fácilmente transferibles desde los usos lingüísticos cotidianos a los usos especializados. Así, muchos docentes creen (o actúan "como si creyeran") que todos los estudiantes que se desempeńan bien en tareas corrientes de lectoescritura como escribir un e-mail o una carta y leer una novela o el diario, podrán 'absorber' rápidamente las claves de escritura y de lectura del derecho por medio de la imitación (de hecho, la imitación, el plagio y el pastiche son las formas tradicionales de aprender a escribir escritos judiciales desde antes que los computadores permitieran el copypaste). El problema es que los estudiantes desaventajados no cuentan con esa capacidad y muchos de los aventajados tampoco, porque la imitación exige homogeneidad sociocultural. Solo aquellos estudiantes que comparten 'el capital cultural' de los abogados podrán aprender de este modo. Todos los demás, en el mejor de los casos, podrían llegar a reproducir textos estandarizados (demandas, sentencias, recursos, escritos, etc.) pero no serán capaces de construir textos nuevos que respondan a los estándares compartidos en el seno de la comunidad jurídica.

Los estudiantes desaventajados no pueden lograr un aprendizaje significativo a través de la imitación porque los textos escritos que circulan

9 En este punto es útil tener a la vista las investigaciones realizadas sobre el modo de trabajo de los escritores aprendices y los expertos. Sobre el particular, Maite Ruiz Flores ha seńalado: "Los modelos de proceso de escritura pusieron de manifiesto la relación indirecta que se da entre la revisión y la planificación. Durante la planificación, el escritor aborda el problema retórico y se hace una representación mental de la tarea que va a realizar. En respuesta a su representación mental de la tarea genera planes y objetivos; esos objetivos guian primero la redacción, pero después se erigen en criterios con arreglo a los cuales evaluar y revisar lo escrito. Esto explica que los escritores inexpertos manifestaran problemas para revisar que estaban precisamente relacionados con deficiencias atribuibles a la planificación, ya que partian de metas excesivamente generales que no era posible utilizar como criterios para revisar. Por este motivo, y pese a que el contraste entre las operaciones de revisión de escritores aprendices y expertos se ha mantenido como referente de la didáctica de la redacción durante décadas, desde hace tiempo hay una tendencia a relacionar el nivel al que se revisa con la representación mental de la tarea. Ya que revisar requiere que el sujeto se realice una representación mental ajustada de la tarea de revisión, tiene sentido que los profesores proporcionemos a los alumnos instrucciones para ayudarles entender qué es lo que implica revisar". Ruiz Flores, Maite (2009) Evaluación de lengua escrita y dependencia de lo literal. Barcelona, Espańa: Editorial Graó, pág. 128. nicas, procedimientos y orientaciones para la enseñanza y aprendizaje de la lectura. Barcelona: Editorial Gedisa, pág. 86. 
en la universidad son altamente estructurados y esa estructura depende de cada área disciplinaria y del propósito que orienta al texto. De este modo quien no conoce 'las claves' de la disciplina y de la comunidad científica ni tampoco los fines que persiguen los textos que lee, no puede ser capaz de atribuir significados ni construirlos.

En vista de lo señalado, los estudiantes deben ser alfabetizados académicamente. La alfabetización primaria o inicial que les permite dominar el idioma y comunicarse en contextos cotidianos no es suficiente para que los estudiantes puedan comunicar información científica dentro de una determinada disciplina. Así, a todo estudiante que ingresa a la universidad se le debe enseñar a leer y escribir 'como abogado', 'como físico', 'como profesor' o 'como médico'. La idea de una alfabetización jurídica inicial consiste en cuestionar la tendencia a creer que los estudiantes que llegan a la universidad por el hecho de haber rendido la PSU ya saben cómo interpretar y elaborar un lenguaje escrito especializado o técnico que es propio de los estudios jurídicos. El problema que tiene la alfabetización académica es que no puede ser realizada únicamente (ni en forma primordial) por especialistas en lenguaje y comunicación: es indispensable la concurrencia de quienes dominan los códigos propios de la ciencia jurídica y de la comunidad jurídica. El aprendizaje de lectoescritura disociado de la comprensión de los conceptos básicos de la disciplina es un trabajo de utilidad solo parcial. Ello por cuanto resulta descontextualizado y como tal resulta difícil de transferir a situaciones que realmente interesan como es el trabajo con códigos, sentencias o textos de dogmática jurídica.

\section{3) DOS COMPETENCIAS DE LAS QUE PREOCUPARSE}

En el marco de un proceso de alfabetización académica es necesario focalizar las habilidades que serán abordadas de modo prioritario. En esa línea, queremos proponer dos competencias que deberían gozar de un grado de preferencia al momento de decidir qué es lo que debiera nivelarse o fortalecerse en los estudiantes. Ellas son: a) La comprensión de textos $y$ discursos habituales en un contexto jurídico, considerando para ello sus dimensiones semánticas, gramaticales y pragmáticas y, b) La construcción de textos y de discursos que sirvan para comunicar los saberes del hablante sobre ciertas categorias jurídicas, como asimismo para dar a conocer sus propios puntos de vista frente a un problema determinado.

\section{1.) COMPRENSIÓN DE TEXTOS Y DISCURSOS}

El dominio de esta competencia no supone conocimientos especializados en derecho, pero sí la capacidad para comprender discursos jurídicos simples, ya sea escritos (textos) u orales (discursos propiamente 
tales) ${ }^{11}$. Los textos a los cuales se alude consisten en diversos tipos de documentos que se leen, usan e interpretan dentro de la comunidad jurídica, tales como: códigos, manuales, sentencias, contratos, artículos de revistas especializadas, reglamentos, opiniones en periódicos, guías de aprendizaje para estudiantes de derecho, monografías, etc. Los discursos, por su parte, son los usos lingüísticos orales que los abogados emplean para comunicarse en diversos contextos; así podemos mencionar como ejemplos: los alegatos en las cortes y en los tribunales orales, las ponencias en congresos disciplinarios, las discusiones informales entre colegas, los planteamientos de profesores en sus clases, etcétera.

Los estudiantes que recién inician sus estudios no requieren, por cierto, comprender todo tipo de textos y discursos jurídicos. Incluso los mejores abogados muchas veces no comprenden cabalmente el sentido de algunos usos altamente sofisticados propios de áreas del derecho que no son de su expertise (¡ni tampoco se espera de ellos que los comprendan en plenitud!). Esta es, en todo caso, una particularidad de cualquier lenguaje profesional. Teniendo en cuenta esta cualidad del lenguaje especializado, la presente competencia se concentra en la capacidad del estudiante para adquirir y usar una 'enciclopedia jurídica básica'12 que le permita enfrentar desde temprano textos y discursos jurídicos de distintos niveles de complejidad, es decir, susceptibles de ser ordenados según el nivel de especialización del lenguaje que se usan.

Naturalmente, el grado de comprensión esperado será diferente según sea el avance curricular del estudiante. Ahora bien, esto no significa que en el primer año solo se deban usar textos de fácil comprensión. Al contrario, no es absurdo afirmar que algunos textos y discursos que estos estudiantes deben preparar son (y es conveniente que sean) bastante más complejos que algunos de los que se trabajan en cursos superiores; ello en vista de la necesidad de proveerles a ellos de un andamiaje conceptual que le servirá de soporte para sus futuros aprendizajes ${ }^{13}$. La opción por el uso de textos de distintos niveles de complejidad lleva a la necesidad

11 Esta competencia se relacionaría con la "capacidad de abstracción, análisis y síntesis" y con la "capacidad para identificar, plantear y resolver problemas"; ambas consideradas como competencias genéricas en el proyecto Tuning $A L$ :

http://tuning.unideusto.org/tuningal/index.php?option=content\&task=view\&id=217\&Ite $\operatorname{mid}=246$

12 Usamos el concepto de 'Enciclopedia' en el sentido de Umberto Eco. La idea central de Eco consiste en representar las relaciones entre todos los significados y/o contenidos categorizados por una cultura usando como modelo teórico e hipótesis de trabajo la imagen de una enciclopedia en donde se contienen todas las interpretaciones posibles de un conjunto de significados finitos. Eco, Umberto (2003) Semiótica y filosofía del lenguaje. Barcelona: Lumen, pág. 133.

13 Piénsese por ejemplo, en la lectura de un libro de Filosofía del Derecho como 'El concepto de derecho' de H. L. A. Hart, frente a un manual dogmático de Derecho Civil como el de Ducci o de Meza Barros. 
de consensuar el criterio de correlación que se usará para asociar el nivel de dificultad de los textos con el grado de comprensión que se exigirá a los estudiantes. No es lo mismo una evaluación que mide competencias básicas de lectura en un texto difícil, que una evaluación de competencias avanzadas en un texto fácil. En principio, es razonable esperar que los estudiantes de primer ańo lean e interpreten los textos difíciles recurriendo solo a competencias básicas de lectura y que, de esa manera, logren solo una aproximación general al sentido del texto; es decir, no comprenderán (de forma autónoma) todos los significados explícitos e implícitos asociados al lenguaje usado. Sin embargo, es sensato pensar que los mismos estudiantes pueden incrementar sus aprendizajes derivados de la lectura si son ayudados en la comprensión del texto (reforzando sus competencias) con apoyos pedagógicos del profesor, los cuales les orientarán en la búsqueda y en el uso de los significados más difíciles de aprehender.

A continuación se realizarán algunas precisiones respecto a lo que se puede esperar que aprendan los estudiantes de primer ańo y, a la vez, se asociarán tales logros a diversos tipos de textos y discursos. Para ello, primero se exponen los diferentes tipos de usos lingüísticos (textos difíciles, sofisticados y sencillos) y luego se exponen ejemplos de diversos grados de comprensión en cada nivel de complejidad.

a.- Textos y discursos difíciles. Lo que caracteriza a estos textos es que los usos lingüísticos son altamente especializados y, a la vez, que el autor asume que estos resultan perfectamente comprensibles para el lector al cual se está dirigiendo (no precisan de explicaciones adicionales) ${ }^{14}$. Así, las comunicaciones de este tipo se han pensado para lectores altamente instruidos en la problemática que se aborda. Estos textos no escatiman el uso de un léxico especializado (palabras técnicas) y no eluden razonamientos sofisticados que, incluso profesionales formados en la misma disciplina, pero no especializados en el área de que se trata, han pasado por alto en sus textos y discursos.

Los textos de este tipo combinan grados importantes de complejidad semántica en estructuras gramaticales, a veces simples, que expresan funciones pragmáticas diversas y habitualmente no explicitadas ${ }^{15}$. Frente

14 Flower ha llamado a esta forma de escribir prosa centrada en el lector (reader-based prose). FlOwER, Linda (n/d). "Revising writter-based prose". Journal of basic writing, No 3, pp. 6274.

15 Es fácil observar que muchos textos especializados usan palabras difíciles que requieren conocimientos lógicos o lingüísticos avanzados respecto de los cuales el uso de un buen diccionario podrá no resultar suficientemente clarificador. Así, por ejemplo, un texto difícil podrá usar palabras tales como heurística, enunciado sintético, proposición anankástica, etc.; o bien podrá hablar de efecto horizontal de los derechos humanos o de normas derrotables. Con todo, también hay textos difíciles que no usan muchas palabras 'raras' pero que sobreentienden que el lector sabe que se ha otorgado un especial significado a palabras 'comunes'. Por ejemplo, Finnis, Dworkin, Hart y Rawls usan la expresión 'justicia' en diver- 
a un texto de léxico complejo el estudiante necesitará leerlo varias veces y requerirá de la orientación de sus profesores para entender el contexto de su elaboración, para identificar los problemas que el texto presenta ( $\mathrm{y}$ su relevancia), como también, para aclarar los puntos en los que debe centrar su atención. A menudo los textos difíciles provocan frustración en el estudiante mientras que el profesor suele descubrir cosas nuevas cada vez que lo relee. A continuación ilustraremos con un ejemplo lo que podría ser un texto difícil para un estudiante de primer ańo, no obstante que en este no se recurre a 'palabras extrañas':

"Nuestro propósito inmediato es explicar el concepto de sistema normativo para analizar luego las propiedades formales de tales sistemas: completitud, coherencia e independencia. La explicación o reconstrucción racional de un concepto es el método por medio del cual un concepto inexacto y vago -que puede pertenecer al lenguaje ordinario o a una etapa preliminar en el desarrollo de un lenguaje científico- es transformado en un concepto exacto o, por lo menos, en más exacto que el primitivo. En lugar de la transformación sería más correcto hablar aquí de la sustitución de un concepto más o menos vago por otro más riguroso"16.

El texto es un buen ejemplo de un texto fácil solo en apariencia. Individualmente todas las palabras figuran en un buen diccionario al alcance de un estudiante de primer ańo, pero solo unos pocos iniciados en el problema que tratan los autores podrán descodificar el sentido que está más allá de la suma de los significados individuales. Evidentemente, muchos significados se explican a lo largo del libro, pero el problema no es ese. El asunto es otro ¿cuántos estudiantes podrán parafrasear y explicar el objetivo de la investigación usando, por ejemplo, el significado apropiado del concepto "análisis"? Probablemente solo aquellos que conocen algo de la historia de la filosofía del derecho del siglo XX -y en especial de filosofía analítica del derecho de raigambre anglosajona- contarán con el conocimiento necesario para la adecuada comprensión del texto (y derivación de ciertas consecuencias de las afirmaciones que los autores realizan). Del mismo modo, solo los iniciados en lógica pueden asignar un correcto sentido a la expresión 'propiedades formales', 'completitud', 'coherencia' e 'independencia'. Lo que se quiere resaltar es que el texto no explicita ninguno de estos conocimientos y por ello es difícil ${ }^{17}$. ¿Qué podemos es-

sos contextos y con significados muy diversos. Estos textos también son difíciles, porque un buen diccionario es completamente insuficiente para explicar el uso teórico-conceptual que cada autor le ha asignado al término.

Alchourrón, Carlos y Bulygin, Eugenio (1993). Introducción a la metodología de las ciencias juridicas y sociales. Argentina: Editorial Astrea, pág. 29. de 'completitud', 'coherencia' e 'independencia'. 
perar del estudiante? A condición de que le entreguen pistas sobre dónde encontrar información de calidad sobre 'lo que probablemente desconoce', es razonable esperar que un estudiante pueda parafrasear y resumir algunos pasajes relevantes de lo leído. También se puede esperar que el estudiante identifique vínculos entre los planteamientos del autor con otros que ya ha conocido ${ }^{18}$. Probablemente el estudiante no podrá construir un buen resumen del texto ni tampoco será capaz de usar el texto en argumentaciones aplicadas a otros contextos nuevos porque la tendencia es a repetir textualmente las palabras leídas.

b.- Textos y discursos sofisticados. Como resulta obvio, estos usos lingüísticos imponen al lector menores exigencias que las que son propias de textos y discursos difíciles. El autor sabe que el texto puede ser leído por profesionales ajenos al círculo de especialistas y por ello generalmente explica los usos técnicos de las palabras y/o explicita los significados connotativos o implícitos aun cuando no rehúye de la precisión. En general, hay dos buenos indicadores para identificar este tipo de textos si su autor es un académico. Primero, su grado de lectura por miembros de la comunidad jurídica; mientras más circule el texto más fácil suele ser. El segundo criterio es la ordenación de los contenidos. Mientras más segmentados se encuentren los contenidos y los argumentos que el texto despliega más fácil es la lectura ${ }^{19}$. De este modo, los textos sofisticados están marcados por una cierta forma de ambigüedad, ya que pueden ser leídos tanto por un especialista (quien los valorará como simples) como por el lego (quien seguramente sentirá bastante inseguridad sobre el correcto sentido). En general, los manuales de dogmática usados en cursos avanzados pueden ser entendidos como textos de este tipo aun cuando contengan pasajes muy complejos y otros muy simples. Veamos un ejemplo:

"Es la ley $\mathrm{N}^{\circ} 16.744$ de 1 de febrero de 1968 la que rige el sistema de accidentes del trabajo.

Pero el sistema actual en su examen resulta diverso, según se examinen los textos o se le aprecie en el hecho jurisprudencial. En efecto, en pocos ámbitos como este se da la transformación de la regla legal por vía jurisprudencial, según observaremos y se hace muy real el conocido brocardo según el cual "la ley es la reina pero la jurisprudencia gobierna".

18 Ejemplos de textos difíciles serían Los derechos en serio de Ronald Dworkin, o Ser y tiempo de M. Heidegger. Algunos textos pueden caer en las tres categorías dependiendo del capítulo que se trate (por ejemplo, Introducción al Derecho de Agustín Squella, Introducción al Análisis del Derecho de C. S. Nino e Introducción al Derecho de Manuel Atienza), o tal vez solo en dos como es el caso de El concepto de Derecho de H. L. A. Hart.

19 Algunos indicadores lingüísticos de la ambigüedad del texto son los marcadores discursivos explicativos y continuativos. Expresiones como: Ahora bien; de este modo; a continuación; en primer lugar; por un lado; en otras palabras; es decir; esto significa que. Son evidencias que permiten suponer que el autor explicará los conceptos usados o retomará la idea que está exponiendo para ayudar al lector a comprender la idea que él quiere comunicar. 
Deberemos pues distinguir el sistema legal y su aplicación práctica para dar cuenta somera del sistema vigente en esta materia [...] Para efectos de la ley, se entiende por accidente del trabajo toda lesión que una persona sufra a causa o con ocasión del trabajo y que le produzca incapacidad o muerte, los ocurridos en el trayecto de ida o de regreso de las labores, los sufridos por los dirigentes sindicales con ocasión del reempeño de sus funciones, excluyéndose solamente los accidentes debidos a fuerza mayor extraña sin relación alguna con el trabajo y los producidos intencionalmente por la víctima, correspondiendo la prueba de las excepciones al organismo administrador" 20 .

Un estudiante de primer año que es enfrentado a textos de este tipo debería, por ejemplo, parafrasear algunas de sus partes y resumir las ideas centrales que se plantean. Debería, además, identificar algunos problemas en la construcción del texto si ha recibido pistas en forma previa por parte de sus profesores ${ }^{21}$. A contrario, sin la ayuda específica del profesor o de un par más aventajado el estudiante seguramente no será capaz de prestar atención a sutiles distinciones que se desarrollan en el texto y, por regla general, no estará en condiciones de refutar los planteamientos que pudieren resultar discutibles.

c.- Textos y discursos sencillos. Un texto sencillo o fácil es aquel que no presenta dificultades al lector no especialista para decodificar sus significados explícitos e implícitos. El autor expresa de forma deliberadamente clara lo que quiere comunicar; el lector atento, por su parte, no tiene dudas relevantes acerca del mensaje y puede reformular lo dicho con sus propias palabras sin errar. Son muchas las variables que hacen que un texto sea fácil. El léxico, la estructura gramatical, la extensión de los párrafos, el uso de explicaciones, redundancias o reformulaciones, las funciones pragmáticas elegidas por el autor y las funciones socioculturales que el texto cumple son algunas de las variables más relevantes.

En general, los textos fáciles, suponen la renuncia a una argumentación integral y/o a la exposición completa de todos los problemas asociados al tema que el texto trata. Así, el texto fácil revela, por ejemplo, que el autor no se hace cargo de ciertas objeciones o que ha decidido sacrificar la profundidad en el tratamiento de los problemas para ganar claridad en el

Domínguez, Ramón (2011) "Los accidentes del trabajo. Historia y visión general de su régimen actual”. En Cuadernos de extensión jurídica, Universidad de los Andes, n 20, pág. 28. Pueden considerarse ejemplos de estos textos, los siguientes: Teoría General del Derecho de Norberto Bobbio, Manual de Historia del Derecho español de Francisco Tomás y Valiente, Derecho privado romano de Alejandro Guzmán B. Autores tradicionalmente muy densos en ocasiones presentan textos de una complejidad mediana (y a ratos sencilla) como es el caso de la Declaración de Granada sobre la Globalización de Jürgen Habermas, David Held y Will Kymlicka Ver en: http://www.elpais.com/articulo/opinion/Declaracion/Granada/globalizacion/elpepiopi/20050606elpepiopi_8/Tes 
lector no instruido en el asunto que se expone. A continuación se reproduce un texto que podría ser calificado como fácil por los estudiantes de primer ańo:

"La iniciativa es la primera fase o etapa del proceso de formación de una ley y consiste en el acto por medio del cual un proyecto de ley se somete a la consideración del órgano o poder legislativo.

Cuando la iniciativa proviene del Presidente de la República, esto es, cuando es esta la autoridad que presenta el proyecto de ley ${ }^{22}$, la iniciativa toma el nombre de mensaje. En cambio, cuando la iniciativa corresponde a uno o más diputados o senadores, toma el nombre de $\operatorname{moción}^{23}[\ldots] "$

El carácter de fácil asignado a un texto o discurso no se vincula inequívocamente con la superficialidad en el análisis. A contrario, en ocasiones, reconocer que un texto como sencillo puede ser un rótulo laudatorio, en cuanto a que se cuenta con la capacidad para disipar pseudoproblemas que no son sino una muestra de confusiones conceptuales. Para que un texto sea calificado como fácil se requiere que el lector domine muy bien la 'enciclopedia' exigida por el autor, pues solo así podrá apostar por un sentido correcto. En otras palabras, solo quien tiene un adecuado dominio de los códigos semántico, gramatical, pragmático y sociocultural que ha usado el autor para construir el texto puede afirmar (sin mucho riesgo) cuál es el verdadero sentido y alcance que este tiene. Considerando estas ideas, se puede decir que los estudiantes que leen estos textos deberían poder parafrasearlos, resumirlos y explicar su estructura y contenido a un auditorio no experto. Deberían también, ser capaces de relacionar el tema con textos y discursos de otras disciplinas fijando las principales diferencias y similitudes y transferir algunas de las ideas desarrolladas hacia otros contextos como, por ejemplo, inventando ejemplos o refutando planteamientos discutibles, etcétera ${ }^{24}$.

A estas alturas, vale la pena detenerse un momento para efectos de aclarar qué es lo que queremos decir cuando hacemos referencia a los códigos semántico, gramatical y pragmático que se encuentran presentes en el lenguaje de los abogados.

22 Obsérvese que el autor con esta aclaración está reforzando el significado de la palabra iniciativa, a pesar de que recién había sido seńalado.

23 En el texto se opta por renunciar a la realización de ciertas precisiones, como es el caso de que las mociones no pueden ser firmadas por más de diez diputados ni por más de cinco senadores. SQuella, Agustín (2004) Introducción al derecho, Santiago: Editorial Jurídica de Chile, pág. 229.

24 Sin perjuicio de que un mismo texto podría caber dentro de más de una categoría (fácil, de mediana complejidad o difícil) pueden hacerse caber aquí manuales tales como: Derecho constitucional de Verdugo, Pfeffer y Nogueira, Historia del Derecho de Ítalo Merello y Derecho Civil de Carlos Ducci. 
Al hablar de código semántico se apunta, por un lado, al dominio de un 'diccionario' de conceptos especializados y por otro, al conocimiento de los contextos sociales en que el uso del código se permite o se prohíbe. Así por ejemplo, los significados asociados a las palabras 'dolo' y 'culpa'25 son muy diferentes según sea el tipo de texto y el contexto en que la palabra se use. Los textos de Derecho Penal de Enrique Cury y de Alfredo Etcheberry las usan (y definen en sentidos diversos debido a sus distintas adscripciones teórico-metodológicas), el Código Civil chileno las define en su título preliminar y muchos textos de Derecho Romano las tratan. Más aún, es común encontrar ambas palabras (en otro sentido) en textos construidos por psicólogos, trabajadores sociales y periodistas de la crónica roja. ¿Cómo elegir cuál es el sentido correcto? La decisión del lector es una apuesta basada en el contexto cultural que se asocia al uso de la palabra. Probablemente, tratándose se lectores legos, la expresión 'culpa' será leída con un significado asociado a su sentido coloquial de 'absolver la cul$p a$ ' o 'echar la culpa' y no al significado que el autor especialista pretende proyectar.

El ejemplo muestra que es muy importante que el profesor pesquise cuál es el significado que se asigna a las palabras y que ejercite la construcción de textos de manera de permitir que el estudiante use el nuevo significado de la palabra, aunque el estudiante solo conozca el significado no jurídico ${ }^{26}$, ya que de otro modo permanecerá el significado coloquial por sobre el sentido técnico y el aprendizaje será memorístico y repetitivo en lugar de conceptual.

25 La RAE las define así: Dolo. (Del lat. Dolus). 1. m. Engaño, fraude, simulación. 2. m. Der. Voluntad deliberada de cometer un delito a sabiendas de su ilicitud. 3. m. Der. En los actos jurídicos, voluntad maliciosa de engañar a alguien o de incumplir una obligación contraída. - bueno. 1. m. Der. Sagaz precaución con que cada cual debe defender su derecho. eventual. 1. m. Der. El que concurre en el autor de un delito que no pretende cometerlo directamente, aunque ha considerado su posibilidad como resultado de su acción. - malo. 1 . m. Der. El que se dirige contra el justo derecho de un tercero. poner - en algo. 1. loc. verb. Interpretarlo maliciosamente.

Culpa. (Del lat. Culpa). 1. f. Imputación a alguien de una determinada acción como consecuencia de su conducta. Tú tienes la culpa de lo sucedido. 2. f. Hecho de ser causante de algo. La cosecha se arruinó por culpa de la lluvia. 3. f. Der. Omisión de la diligencia exigible a alguien, que implica que el hecho injusto o dańoso resultante motive su responsabilidad civil o penal. 4. f. Psicol. Acción u omisión que provoca un sentimiento de responsabilidad por un dańo causado. - teológica. 1. f. Pecado o transgresión voluntaria de la ley de Dios. absolver a - y pena. 1. loc. verb. Absolver plenariamente, como en los jubileos. echar la - a alguien. 1. loc. verb. Atribuirle la falta o delito que se presume ha cometido.

26 Puede haber también partes más o menos extensas de los textos en que por el uso de un lenguaje muy sofisticado o altamente formalizado, sea esperable que el lector se salte algunas de sus partes y no por ello deje de ser un lector competente de aquellas partes que sí interesan (por ejemplo, Introducción a la metodología de las ciencias juridicas y sociales de Alchourrón y Bulygin). 
El código gramatical es el conjunto de estrategias de organización de la información que se expresan en estructuras discursivas y argumentales y en marcadores lingüísticos. Conocer la organización de un texto o discurso supone conocer ya el contexto sociocultural en que se elaboró y en el cual puede ser leído o escuchado. Así, el dominio de este código implica que el lector es capaz de comprender cómo se jerarquizan los contenidos y los argumentos mediante estructuras discursivas o argumentales. Así como todos sabemos que una novela se ordena en capítulos y que salvo excepciones - Rayuela de Julio Cortázar es una de ellas- es recomendable leer el texto según la secuencia de capítulos, por su parte, todos los abogados chilenos saben que en una sentencia penal, el voto disidente se ubica al finalizar una sentencia, que la exposición de los hechos da inicio el texto y que si queremos saber cuál fue la decisión debe leerse primero la parte resolutiva, la cual se ubica a continuación de la parte considerativa.

Además del conocimiento de las relaciones de ordenación, subordinación, coordinación o adición de información en el texto, un lector que domina la gramática de los textos jurídicos entiende que un manual de estudio 'se escribe y se lee distinto' que una sentencia judicial, un auto acordado, un artículo científico o un reglamento. En artículos científicos, por ejemplo, es obligatorio que el autor exprese su posición y la distinga de otras similares o rivales. En sentencias judiciales el juzgador debe valorar los medios de prueba; y en los actos legislativos habitualmente se expresan las valoraciones que inspiran las modificaciones. En todos estos casos, casi nunca se usan expresiones de valoración que impliquen un alto compromiso afectivo del autor. La regla gramatical implícita en la cultura jurídica puede expresarse así: el autor tiene permitido expresar su valoración de forma velada o intelectualizada y tiene prohibido dejar explícitos sus sentimientos. Por ello, expresiones como: 'me gusta'; 'me desagrada'; 'no quiero'; 'no me parece'; 'es indeseable' son usos proscritos en los textos indicados (salvo, por ejemplo, que el autor parafrasee los dichos de un tercero como un testigo); mientras que, en algunos pasajes de los mismos textos, son permitidas expresiones tales como: 'no se aprecia daño'; 'se valora un error'; 'se estima como razonable'; 'se ha ponderado'; 'a juicio de este sentenciador', etcétera.

Los marcadores argumentativos también son usados de forma diferente según sea la gramática del texto. El significado asociado a la expresión 'Por tanto' en los escritos judiciales es muy diferente a la que se le otorga en contextos académicos en donde es muy escaso su uso. Del mismo modo, conectores como: 'porque'; 'pues'; 'ya que'; 'además'; 'entonces'; 'por ello'; 'ahora bien'; 'si, y solo sî; 'sin embargo'; 'más o menos' entre otras, permiten asociar la información precedente con la que les sucede transmitiendo significados de causalidad, concatenación, separación, adición, oposición o de proximidad. Debido a su impacto, los académicos cuidan 
bastante el uso de estos marcadores en la escritura de las conclusiones de un artículo científico. Difícilmente una investigación cualquiera concluirá usando la expresión 'más o menos' 27 , que significa aproximación y relatividad en lo que se dice. En su lugar, el autor privilegiará el uso del 'porqué que resulta útil para establecer relaciones de causalidad y, a la vez, para comunicar seguridad en aquello que se está diciendo.

El dominio de los códigos pragmático y sociocultural supone identificar la fuerza que se asocia a cada texto y, a la vez, el rol que el texto cumple en la comunidad jurídica y en otras comunidades. El lector que domina estos códigos conoce los efectos y las consecuencias que se derivan de las palabras y puede reconstruirlos. Parafraseando a J.L. Austin, el lector avezado puede hacer cosas con palabras. Por ejemplo, el lector formado en la filosofía analítica capta rápidamente que en libros como 'Distinguiendo' de Riccardo Guastini o 'Sobre el Derecho y la Justicia' de Alf Ross se persiguen fines distintos que los que se asocian a las Explicaciones de Derecho Civil Chileno y Comparado de Luis Claro Solar, al Tratado de Derecho Penal de Hans-Heinrich Jescheck o incluso a la Teoría de la Argumentación Jurídica de Robert Alexy. En los primeros se privilegia la función descriptiva del lenguaje por sobre la prescriptiva; en los segundos, en cambio, y a veces de manera indirecta, se pretende influir en cómo deben ser las cosas buscando justificar la mejor lectura de las normas vigentes en un sistema jurídico determinado. El abogado litigante sabe, por su parte, que los fragmentos de una sentencia deben ser cuidadosamente leídos si se la quiere impugnar y, a la vez es capaz de reconocer en la ley las enumeraciones taxativas de las que no lo son. Así también el abogado domina el valor sociojurídico que poseen las sentencias del Tribunal Constitucional y puede pronosticar el impacto de un Auto Acordado dictado por la Corte Suprema o lo que implica que en una sentencia que resuelve un recurso de protección exista un voto disidente.

Explicitar las reglas que gobiernan a los textos es una tarea muy importante sobre todo si se trata de estudiantes cuyo entorno cultural no coincide con el que es habitual entre los miembros de la comunidad jurídica. Es muy probable que los estudiantes desconozcan el significado político, ideológico, cultural o ético que está implicado en un texto o discurso. Sobre todo si se trata de textos difíciles. De la misma manera, habitualmente los estudiantes asignarán cargas emotivas fuertes a ciertos conceptos y les resultará difícil sustraer esa carga a las palabras para aprehender un concepto eminentemente técnico.

Aunque el ejemplo es trivial, no es lo mismo referirse a los eventos políticos de la década de 70 como 'Golpe militar' que decir que se trató de

27 Otro significado para la misma expresión aparece en la definición de testamento del Código Civil donde se indica que se trata de un acto 'más o menos solemne'. 
un 'Pronunciamiento militar' o afirmar que 'la pretensión de Pedro es sólo una mera expectativa' que decir que 'la pretensión de Pedro es sólo un deseo' o que 'la acción de Pedro discrimina positivamente a las mujeres'.

En conformidad a lo expresado, se podrían suscribir las palabras de Umberto Eco en cuanto a que "Un texto es una máquina perezosa que espera que el lector haga parte de su trabajo" 28 . Así, para atribuir significado a los textos cuya lectura es requerida al estudiante de la carrera de derecho, se precisa que este sepa cómo completar los vacíos inevitables que lo afectan, así como también elegir de manera adecuada entre distintas formas de interpretarlos. Todo ello lleva a que se requiera transferir de manera temprana ciertas reglas que definen la manera en que los textos jurídicos deben ser leídos.

\section{2.) CONSTRUCCIÓN DE TEXTOS Y DE DISCURSOS ${ }^{29}$}

Como se sabe, el lenguaje puede servir a distintos fines: informar, influir, sorprender, condenar, intimidar, demostrar, divertir, presionar, afligir, otorgar reconocimiento, etc. ${ }^{30}$. En vista de ello, para que se produzca una comunicación adecuada, se precisa que el lector u oyente competente comprenda rápidamente la finalidad del autor o emisor para así no errar en el significado que se está intentando transmitir (por ejemplo, entender como una descripción lo que en realidad es una ironía o una broma puede resultar desastroso) ${ }^{31}$. Pero, por cierto, aquello no basta ya que se precisa que el emisor y receptor compartan, además, una cierta manera de construir e interpretar ideas o representaciones del mundo a través de palabras y estructuras gramaticales estándar.

En muchas oportunidades, quien se enfrenta a un texto o discurso cuenta con señales explícitas en cuanto a la manera que deberá ser comprendido. Así, si el texto indica que se trata de una novela, el lector estará advertido de que el autor no busca describir sucesos ni dar órdenes (como sí sería esperable de un noticiero o de un reglamento, respectivamente),

Eco, Umberto (1996) Seis paseos por los bosques narrativos. Barcelona: Lumen, pág. 59.

Esta competencia se relacionaría con la "Capacidad de comunicación oral y escrita" y con la "Capacidad de aplicar los conocimientos en la práctica"; ambas consideradas como competencias genéricas en el proyecto Tuning $A L$. Ver en:

http://tuning.unideusto.org/tuningal/index.php?option=content $\&$ task=view \& id $=217 \&$ Ite $\operatorname{mid}=246$

Ver, por ejemplo, Carrió, Genaro (1990) "Lenguaje, interpretación y desacuerdos en el terreno del derecho" en el mismo: Notas sobre derecho y lenguaje. $4^{\mathrm{a}}$ ed. Buenos Aires: Abeledo-Perrot, págs. 38-39.

Uno de los casos más famosos de error en la identificación de la función del lenguaje es el que se dio en el ańo 1938 cuando se emitió en New York un programa radial dirigido por el, entonces, joven actor Orson Welles. En este se anunció la invasión de los marcianos a Estados Unidos lo que provocó pánico entre millones de radioescuchas hasta el momento en que Welles anunció "esto ha sido un radioteatro". 
sino que le estará permitido inventar datos o crear mundos imposibles que provoquen emociones o que hagan reflexionar al lector acerca de su vida o, tal vez, sobre la opresión en ciertos lugares del mundo. Por su parte, si el presentador de un espectáculo anuncia a un humorista, el público ya sabrá que lo que este diga tiene como propósito divertirlo y que, por tanto, no debe ser tomado en serio. En la comunidad de los abogados, el seńalar que un texto es un manual o un reglamento, o bien que un discurso corresponde a una ponencia o a un alegato, pone sobre aviso al auditorio respecto de la forma en que este deberá ser comprendido.

Según resulta evidente, el dominio de esta competencia comunicativa se relaciona directamente con el dominio de la primera competencia básica desarrollada, esto es, de comprensión de textos y discursos. La razón es simple: la principal evidencia con la que cuenta el profesor para medir el nivel de comprensión que el estudiante logró es la performance comunicativa del estudiante. Es razonable pensar, por ejemplo, que un texto plagado de faltas ortográficas y gramaticales y que usa un léxico poco adecuado al contexto, ha sido escrito por un autor que conoce bastante poco del significado que se espera sea transmitido. A contrario, tendemos a pensar que lo dicho por un autor que no comete esos errores revela un buen nivel de comprensión de textos y de discursos que le han servido de soporte.

Una adecuada y oportuna transmisión de los saberes jurídicos acumulados a quienes estudian Derecho resulta clave para el éxito de su proceso de formación: de otra forma los actuales estudiantes no podrán llegar a insertarse el día de mańana en la comunidad de los abogados. En razón de ello, los buenos profesores requieren ir verificando regularmente el nivel de comprensión que se ha alcanzado de los textos y discursos a los cuales los estudiantes son expuestos. La tarea puede abordarse en distintos niveles de profundidad, ya sea pidiendo que se parafrasee lo que ha sido dicho, que se aplique para la solución de un caso inventado, que se relacione con puntos de vista sostenidos por otros autores, que se sintetice o que se realice un juicio crítico. Cualquiera sea la técnica utilizada para la transmisión de los aprendizajes asociados a textos y de discursos en general (salvo la reproducción puramente memorística), ella presupone la adecuada comprensión de aquellos por parte de la persona que emprende dicha tarea. Así, por ejemplo, si el estudiante no comprende integralmente todas las dimensiones de un tipo de texto (por ejemplo, las sentencias judiciales) no será capaz de explicarlo ni de construir un nuevo texto en que se cumplan todas las funciones que la comunidad jurídica les asigna. Este amplio concepto de comprensión del texto incluye la manera en que el texto se relaciona con otros formando una red al interior de la comunidad jurídica, incluso conectándose en varios puntos con textos pertenecientes a otras disciplinas. 
Quienes pertenecen a la comunidad de los abogados saben que los textos y discursos jurídicos deben ser entendidos, construidos y transmitidos de determinada manera. Por ejemplo, la transmisión del artículo de una ley exige una alta fidelidad con las palabras en que este se encuentra formulado, no ocurriendo lo mismo cuando se trata de dar a conocer el punto de vista de un autor acerca de la manera en que debe ser interpretado un determinado texto normativo, donde se admite la paráfrasis, el resumen, la reconstrucción de las ideas respetando lo esencial del mensaje transmitido, etc. A su vez, la escritura de textos jurídicos exige que el autor ponga especial cuidado en respetar su estructura estándar. Esto no apunta a que se ajuste a las reglas formales (interlineado, tipo de fuente, tamaño de la hoja o márgenes), sino que implica conocer cuáles son las partes que componen cada tipo de texto y comprender las razones que subyacen a la forma de composición. El modo de escribir una demanda es diferente al que impone la sentencia judicial; incluso podría afirmarse, con mayor precisión, que la exposición de los hechos en una demanda no se organiza del mismo modo que en una sentencia.

Naturalmente, dependiendo del tipo de texto del que se trate, la estructura narrativa y que le otorga su identidad será más o menos flexible. En el mundo jurídico es posible encontrar textos y discursos altamente estructurados como los alegatos, las objeciones en juicio y las sentencias judiciales y, por otro lado, textos muy desestructurados como los debates sociales, las conversaciones entre colegas o la información que se le suministra al cliente. En general, es posible alinear el grado de estructuración de un texto con el auditorio al cual se dirige y con su grado de dificultad. Sin embargo, esto no significa que un texto muy estructurado sea siempre un texto difícil que se orienta a un público especializado, ni viceversa. La estructura textual provee un orden de lectura, una jerarquía de significados y contenidos y una secuencia de información que puede facilitar la lectura comprensiva del texto (a condición de que el lector conozca tal forma de organización). Por eso los abogados litigantes saben perfectamente que al leer una sentencia lo primero que se lee no es el primer considerando sino aquel en donde se señala la resolución (y que, por regla general, se ubica casi al finalizar el documento).

La construcción de los textos y discursos de parte de los estudiantes debe ajustarse a las características propias de la cultura dominante de los abogados y es deber del profesor comunicar esos requisitos de forma explícita. Por ejemplo, es labor del profesor informar al estudiante de las reglas de cortesía lingüística dominantes en la comunidad jurídica. El estudiante no sabe que los jueces deben ser llamados 'magistrados', que los miembros de Cortes de Apelaciones deben ser tratados de 'Su señoría ilustrísima', que en los escritos judiciales son verbos clave 'ruego', 'pido', 'solicito' y que es lingüísticamente erróneo incluir en una demanda ver- 
bos como 'quiero', 'deseo', 'aspiro' al escribir la parte petitoria. Creemos, siguiendo a Cassany, que es bueno tener algunas preguntas en mente al momento de plantear un ejercicio o actividad didáctica para que los estudiantes lo resuelvan y entre ellas destacan: ¿cuáles son las necesidades de comunicación que tendrán mis estudiantes cuando ejerzan como abogados?, ¿qué textos tienen que comprender?, ¿qué textos deben saber producir?, ¿qué conocimientos lingüísticos y extralingüísticos (sociales, culturales, éticos) tienen que dominar para comprender y/o producir estos textos con la máxima corrección y adecuación posibles?, ¿qué actitudes es bueno trabajar para que las actividades expresadas por las interrogantes anteriores se desarrollen con fluidez y provecho?32.

La dimensión comunicativa del lenguaje jurídico no puede ser descuidada si se quiere formar buenos abogados. Es muy corriente que los abogados se comuniquen no solo con otros colegas, sino también con profesionales de otras disciplinas y con legos. Un buen abogado debe poder moderar sus usos lingüísticos de un modo tal que su interlocutor le comprenda bien. No es lo mismo hablar de un problema jurídico con un especialista, que con un ingeniero, con un médico, con un trabajador social, con un bioquímico o, simplemente, con un cliente. En palabras simples, en ciertos contextos un buen abogado es como un buen traductor.

De acuerdo a lo expresado, se distinguen claramente al menos tres tipos de comunicación claramente diferenciados: entre especialistas de una misma disciplina, entre profesionales de especialidades diferentes y entre un especialista y un lego. Desde la perspectiva del estudiante, una situación típica del primer caso es una evaluación oral o escrita de un curso de nivel superior. El segundo caso puede ocurrir en diálogos enmarcados en cursos dictados por otras facultades de la universidad, y el tercer caso probablemente se limite a instancias de comunicación del estudiante con su familia o en los cursos prácticos contemplados por el plan curricular.

Del heterogéneo conjunto de textos que participan del mundo jurídico, unos de los más importantes de aprender a leer y a escribir son aquellos que resuelven o buscan influir en la manera de resolver problemas de connotación jurídica mediante la invocación de normas en un caso concreto. Las demandas, los recursos y las sentencias son buenos ejemplos, pero también lo son los informes en derecho, los alegatos en las cortes y los comentarios de jurisprudencia. No se corre mucho riesgo si se afirma que la comunidad jurídica chilena considera que estos textos poseen un estatus jurídico privilegiado: ¡por algo los jueces deben ser abogados, la defensa ante tribunales está reservada a los abogados y los notarios dejan constancia de los abogados que han redactado minutas de 
escrituras públicas! Ahora bien, todos estos textos y discursos combinan, grosso modo, dos grandes estructuras textuales: la narración de hechos y la argumentación dogmática. Dado que la eficacia comunicativa del texto depende del éxito que se alcance en ambas estructuras, es crucial que un estudiante aprenda a manejarlas desde temprano.

En el caso de la narración de hechos los principales problemas que debe resolver el escritor competente están dados, por ejemplo, por la determinación de la relevancia e irrelevancia de los datos disponibles y, a su vez, por la textualización adecuada de la información relevante, es decir, de usar todos sus conocimientos semánticos, gramaticales, pragmáticos y culturales para realizar dos acciones conjuntas: (i) contar la historia que debe relatar de modo tal que el juez u otro lector articule sin dificultad los hechos con la condición de aplicación de la norma que se invoca en la parte argumental del texto y (ii) proyectar esa historia en los medios de prueba de que dispone (o que cree accesibles) para satisfacer los estándares de prueba del procedimiento de que se trate ${ }^{33}$.

Al elaborar la sección argumentativa, la escritura también debe ajustarse a ciertos lineamientos. El autor del texto debe anticipar las posibles objeciones y réplicas, determinar las fuentes del derecho que es admisible invocar, ponderar la conveniencia de fundar la argumentación solo en reglas, o en una combinación de reglas y principios, determinar cuál es la interpretación de normas que resulta más conveniente en atención al auditorio, etc. Seguramente, esta sección de los textos jurídicos en casos fáciles (easy cases) presenta baja dificultad e incluso un buen abogado podría permitirse realizar 'copy-paste' de la argumentación disponible en un caso análogo. Los problemas se presentan con la escrituración de argumentaciones en torno a casos difíciles (hard cases) y entonces parece sensato afirmar que los estudiantes deben ser entrenados en la argumentación sobre este último tipo de controversias. Evidentemente, la diferenciación entre cuál es un caso fácil y cuál uno difícil presupone que se ha identificado de forma correcta el problema que debe resolverse. Es diferente construir un texto para solucionar un problema abstracto (por ejemplo, cuáles serían las interpretaciones potencialmente aceptables de un texto normativo) que escribir un texto para resolver un problema concreto (por ejemplo, cuál es el derecho aplicable a un caso que ha aparecido en las noticias). El conocimiento y comprensión de la narración se traduce en estudiantes de derecho mejor formados. El estudiante capaz de componer o descompo-

Aquí no nos referimos a los problemas de escrituración del texto, sino que solo a los vinculados a la organización de las ideas que lo conforman. Naturalmente, la clasificación y distribución de las ideas que componen el texto y, posteriormente su instanciación en los distintos párrafos del texto de un modo funcional al propósito que el escritor busca conseguir presenta un conjunto de desafíos que no nos es posible afrontar en este trabajo. Serafini, María Teresa (2008). Cómo se escribe. Paidós, Buenos Aires, Argentina, p. 134. 
ner la estructura de una narración jurídica y de identificar las condiciones de aplicación de la norma aplicable al suceso narrado es un estudiante capacitado para identificar los puntos de prueba del caso concreto y resolver problemas jurídicos, o bien impugnar decisiones judiciales.

El estudio de la estructura narrativa y argumentativa del discurso jurídico importa desafíos a la forma de enseñar el derecho al interior de una comunidad universitaria determinada. Siendo el discurso jurídico preferentemente escrito, es indispensable que el estudiante sepa identificar la estructura y los rasgos lingüísticos de los textos de estudio. Parodi señala que la universidad deberá formar en sus estudiantes la conciencia de que algunos materiales escritos formarán parte de su vida profesional y deberán aprender no solo a leerlos, sino también a escribirlos ${ }^{34}$. La 'narración jurídica' puede ser caracterizada como parte de un discurso especializado, porque se origina dentro de una comunidad que construye su propia identidad, con elementos lingüísticos y convencionales propios. La pregunta clave, entonces, es ¿quién va a leer el texto? Sin perjuicio que los textos que construimos los abogados pueden ser leídos por diferentes personas, el auditorio que nos preocupa y condiciona su estructura será el de nuestros colegas. Así, no nos quitará el sueño si otros profesionales nos llegan a catalogar de pedantes, crípticos o excesivamente solemnes, si es que ello fuere el precio a pagar por la construcción de un texto que resulte significativo para la comunidad de los abogados y de los jueces.

\section{4) BREVES CONSIDERACIONES SOBRE LA EVALUACIÓN}

Un aspecto que determina fuertemente el impacto de nuestras prácticas pedagógicas encaminadas a fortalecer la (sub)competencia de construcción de textos, es la corrección o evaluación (usamos estos conceptos como sinónimos) de los ejercicios entregados a los estudiantes. Aquí hay dos problemas, por un lado, siempre hay una tensión entre la corrección que busca la mejora del texto y la que simplemente pretende justificar la calificación y, por otro, es un problema que las evaluaciones siempre se concentren en los errores de los estudiantes y, por lo general, estos errores son aquellos que tienen que ver con la ortografía, puntación, márgenes o léxico y no con los aspectos de más valor en un texto: los vinculados a la estructura argumental o con la organización de la información dentro del texto o discurso. Para resolver el primer problema se debe considerar que el proceso de generación del texto o discurso debe ser explícitamente enseñado y coherentemente evaluado. Así, el estudiante debe recibir retroalimentación sobre su desempeño en versiones preliminares o borradores 
del texto y en simulaciones de discursos orales que le permitan mejorar su trabajo en una nueva oportunidad antes de la entrega final. Naturalmente, la retroalimentación debe ser clara sobre cuáles son los errores detectados y cuáles pueden ser las estrategias para superarlos. Es necesario que el estudiante pueda comparar 'su error' con una versión mejorada del texto propuesta por el profesor que, al igual que un modelo, permita al estudiante reflexionar sobre cómo debe hacer la tarea para lograr el objetivo establecido en el ejercicio ${ }^{35}$.

El segundo problema es más complejo de solucionar porque se deben distinguir las causas de los errores. Primero, hay una cuota importante de errores que tienen que ver con que el estudiante no conoce suficientemente el código lingüístico como para poder dar forma a sus pensamientos del modo correcto (como el profesor espera que lo haga). En segundo lugar, muchos estudiantes escriben usando un registro lingüístico que es usado en conversaciones coloquiales porque desconocen la sintaxis del registro académico escrito. En tercer lugar, hay muchos errores que son fruto del azar, de un descuido o de falta de atención. En cuarto lugar, están los errores que surgen porque el estudiante trabajó con una hipótesis de trabajo errónea ${ }^{36}$.

Con esta breve tipología de los errores, es fácil percibir que muchos profesores se concentran solo en un tipo de error (aquellos objetivos de fácil justificación como las faltas de ortografía) y no evalúan errores 'sustantivos', es decir, los errores que muestran cómo y por qué el estudiante usó relaciones conceptuales equivocadas para construir su texto. Es fácil apreciar la importancia de este asunto. Si los errores 'sustantivos' son errores importantes y graves, porque afectan la capacidad del texto de comunicar el mensaje que su autor espera transmitir y hacen que el texto o el discurso padezcan de algún grado de ininteligibilidad, es más grave aún que los profesores no sean capaces de evaluar estas equivocaciones y de justificar ante los estudiante la valoración de un texto. Es importante entonces, antes de presentar un ejercicio de escritura, revisar qué es lo central ¿es más importante que el estudiante incluya todas las ideas relevantes o que no incurra en errores ortográficos (tildes, b/v, c/z, entre otras)? ¿evaluaré el uso de un lenguaje formal, técnico y jurídicamente apropiado o, en cambio, permitiré que se usen formas coloquiales de expresión? La ponderación de estas disyuntivas es crucial, ya que sobrevalorar la ortografía impide trabajar la coherencia, la cohesión y la originalidad el texto $y$, del mismo modo, sobreestimar la formalización del lenguaje (suponiendo que un léxico técnico es una buena evidencia de un alto dominio

35 Cassany, Daniel (2009). Reparar la escritura. Didáctica de la corrección de lo escrito. Barcelona Editorial Graó.

36 Ruiz Flores, Maite (2009). Evaluación de lengua escrita y dependencia de lo literal. Barcelona Editorial Graó. 
del tema) por sobre una redacción clara y simple puede impedir que el estudiante aprenda los conceptos y que tome conciencia del proceso que implica el acto de escribir ${ }^{37}$.

\section{CONCLUSIONES}

El delicado estado por el que atraviesa la enseńanza del derecho -en un contexto en que las bases sobre las cuales se edifica ha experimentado un fuerte remezón- hace necesario revisar en profundidad la manera en que se abordan los aprendizajes que suponen la lectura y escritura de textos, como también la comprensión y elaboración de discursos orales. Evidentemente no nos referimos al uso del lenguaje coloquial para enfrentar estas tareas, sino que al uso de un lenguaje propio de los abogados. Para tales efectos resultaría altamente recomendable tener en consideración los aspectos que a continuación se señalan. Algunos de ellos los hemos desarrollado en el presente trabajo y otros debieran dar pie a investigaciones futuras:

En primer lugar, hay que decir que la enseńanza del derecho en Chile nunca ha enfrentado la enseñanza del lenguaje jurídico de modo explícito. Es preciso reconocer, sin embargo, que a partir de reformas a la legislación y de la creciente valoración de la oralidad en muchos procedimientos, la enseńanza del derecho ha comenzado a dar cierta prioridad a algunas destrezas en un contexto de expresión verbal del pensamiento: así hoy, diez ańos después de la reforma procesal penal, casi no existen escuelas de derecho sin un aula que replique una sala de audiencias de juicio oral. Ahora bien, esta forma de enseñar 'destrezas de litigación' suele carecer de base epistemológica (y lingüística) y solo se limita a promover que el estudiante replique los modos, rutinas, turnos y prácticas que los abogados y jueces acostumbran realizar en las diferentes audiencias. En el mismo sentido, la enseńanza de la escritura tampoco cuenta con bases claras. En el modelo de enseñanza tradicional basado en la memorización de los contenidos expresados en los códigos, los estudiantes aprendían a usar el lenguaje jurídico por repetición e imitación y el sistema tenía cierto grado de eficacia en la medida en que los estudiantes eran culturalmente muy homogéneos. Si se quiere superar ese modo de alfabetización académica y se aspira a abarcar grupos de estudiantes culturalmente heterogéneos, es indispensable desarrollar nuevas estrategias de enseñanza del lenguaje jurídico escrito. Para ello el primer paso es reformular la comprensión del proceso de aprendizaje abandonando la idea de que el estudiante es una tabula rasa que recibe, de modo pasivo, los contenidos que el profesor entrega. El proceso de aprendizaje debe entenderse como una 
formulación y reformulación continua de ideas mediando una contrastación entre ellas. El trabajo del estudiante se asemeja entonces al de un científico que formula hipótesis provisionales sobre algún problema cuya verdad o falsedad es aún incierta ${ }^{38}$.

En segundo lugar $-y$ de manera consistente con lo que recién ha sido indicado- no hay carreras de derecho que cuenten con planes de enseñanza de competencias de lectoescritura que sean especializados en el uso del lenguaje jurídico. Si bien existen programas propedéuticos, remediales o introductorios a la vida universitaria, todos ellos buscan el desarrollo de competencias de lenguaje y comunicación en contextos coloquiales y formales extrajurídicos. Este problema tiene su causa en la separación que existe entre los programas de nivelación y los contenidos de la malla de estudios de derecho. Esta disociación aumenta los costos, duplica los esfuerzos y es muy ineficiente porque exige que el estudiante, de modo autónomo, transfiera los conocimientos lingüísticos desde contextos extrajurídicos a contextos jurídico-normativos. En palabras simples, lo que los estudiantes aprenden es a usar 'mejor' el lenguaje en contextos de cotidianeidad y no en relación a instancias propias de los estudios jurídicos ${ }^{39}$.

En tercer lugar, es necesario destacar el conocimiento de las reglas lingüísticas por parte de los estudiantes. Mientras más lingüística sabe un estudiante, más y mejor será su avance en el dominio de las competencias de lectoescritura. Ahora bien, estos conocimientos no se limitan a las reglas de ortografía, sino que a un dominio profundo de cómo el lenguaje se organiza según el contexto para comunicar un determinado mensaje. Como ya hemos dicho, la corrección de los errores ortográficos es muy fácil porque es muy objetiva, pero no es tan fácil corregir un texto en términos de su cohesión, coherencia o alineación con las reglas socioculturales que dominan el contexto. En estos niveles, para mostrar los errores y explicar las razones que los justifican es indispensable que los estudiantes sepan de qué se habla. Así, por ejemplo, si un texto tiene problemas de cohesión: "El acusado alegó en su defensa que habia obrado por ignorancia pero, aunque en mi opinión era inocente, sin embargo el tribunal lo condenó...”, cómo se le explica su error al estudiante si él no sabe cuál es rol que cumplen los conectores adversativos (pero; sin embargo; aunque) y cómo se deben insertar los comentarios en un texto (en mi opinión era inocente).

38 Klimovsky, Gregorio (1985) "El concepto de ciencia. Problemas de la ciencia", primer seminario sobre metodología de la ciencia, Facultad de Arquitectura y Urbanismo, Buenos Aires: UBA-OEA.

39 De lo que conocemos, una de las pocas experiencias exitosas en este sentido sea el curso de Cultura, Lenguaje y Derecho que introdujo deliberadamente la Universidad Austral en el primer semestre del plan de estudios de Derecho; como también algunas versiones de los Talleres de Análisis Jurídico en la Universidad Diego Portales. En la Universidad Católica de Temuco este último curso se dictó exitosamente sólo entre 2005 y 2011, los ajustes al plan curricular introducidos este ańo no valoraron estos aprendizajes. 
Naturalmente, este modo de entender el trabajo con los estudiantes exige de un especialista (probablemente de un lingüista) que pueda acompañar al profesor en la generación de instancias de aprendizaje y a los estudiantes en la corrección de los ejercicios.

En cuarto lugar, es necesario enfocar el problema en los estudiantes desventajados como grupo. Las instituciones educativas necesitan comprender que al admitir estudiantes que no cumplen el perfil de ingreso asumen un riesgo, un costo y una responsabilidad. El riesgo de deserción $\mathrm{y}$, en general, de fracaso académico de los estudiantes desaventajados es mayor, y, por cierto, los procesos de nivelación exigen recursos que podrían orientarse a satisfacer otras necesidades que también apremian. La pregunta es: ¿qué grado de desventaja es tolerable?, es decir, ¿hasta dónde podemos nivelar? La cuestión no es sencilla y, al menos por ahora, no aventuraremos una respuesta.

\section{BIBLIOGRAFÍA}

- Alchourrón, Carlos; Bulygin, Eugenio (1993) Introducción a la metodología de las ciencias jurídicas y sociales. Buenos Aires: Editorial Astrea.

- Assous, Gisèle; Attar, Colette (2003). "Leer un texto matemático". En El poder de leer. Técnicas, procedimientos y orientaciones para la enseñanza y aprendizaje de la lectura. Barcelona: Gedisa.

- Brunner, José Joaquín; Elacqua, Gregory (2003). Informe de capital humano, Universidad Adolfo Ibáñez. Disponible en: http:// www.oei.es/etp/informe_capital_humano_chile_brunner.pdf

- Carr, Nicholas (2011). Superficiales ¿Qué está haciendo Internet con nuestras mentes? Traducción de Pedro Cifuentes. Bogotá: Taurus.

- Carrió, Genaro (1990) "Lenguaje, interpretación y desacuerdos en el terreno del derecho". En él mismo: Notas sobre derecho y lenguaje. $4^{\mathrm{a}}$ ed. Buenos Aires: Abeledo-Perrot.

- Cassany, Daniel; Luna, Marta; Sanz, Gloria (2008). Enseñar lengua. Barcelona: Editorial Graó.

- Cassany, Daniel (2009). Reparar la escritura. Didáctica de la corrección de lo escrito. Barcelona: Editorial Graó.

- Coloma, Rodrigo (20ir). "Cuando los árboles no dejan ver el bosque, o: ¿Qué (y cuánto) debe enseñarse a un estudiante de derecho?”. En Agüero, Claudio (CoOrd.). La relevancia de la enseñanza del Derecho. Edición independiente del proyecto MECESUP UCT0707.

- Cossem, Michelle (2003). "Leer y escribir una relación dialéctica”. En El poder de leer. Técnicas, procedimientos y orientaciones para la enseñanza y aprendizaje de la lectura. Barcelona: Gedisa. 
- Declaración de Granada sobre la Globalización de Jürgen Habermas, David Held y Will Kymlicka Ver en: http://www. elpais.com/articulo/opinion/Declaracion/Granada/globalizacion/ elpepiopi/20050606elpepiopi_8/Tes

- Domínguez, Ramón (201 I) "Los accidentes del trabajo. Historia y visión general de su régimen actual”. En Cuadernos de extensión jurídica, Universidad de los Andes.

- Eco, Umberto (1996). Seis paseos por los bosques narrativos. Barcelona: Lumen.

- Eco, Umberto (2000). Semiótica y filosofía del lenguaje. Barcelona: Lumen

- Flower, Linda. "Revising writter-based prose". Journal of basic writing, No 3, pp. 62-74.

- Klimovsky, Gregorio (1985). "El concepto de ciencia. Problemas de la ciencia". En Primer seminario sobre metodología de la ciencia, Facultad de Arquitectura y Urbanismo, Buenos Aires: UBA-OEA.

- Parodi, Giovanni (ED.) (2005). Discurso Especializado e Instituciones Formadoras. Valparaíso: Ediciones Universitarias de la Pontificia Universidad Católica de Valparaíso.

- Ruiz Flores, Maite (2009). Evaluación de lengua escrita y dependencia de lo literal. Barcelona: Editorial Graó.

- Serafini, María Teresa (2008). Cómo se escribe. Buenos Aires: Paidós.

- SQuella, Agustín (2004). Introducción al derecho. Santiago: Editorial Jurídica de Chile.

- Vygotsky, L. S. (1978). Mind in society: The development of higher psychological processes. Cambridge, MA: Harvard University Press. 